\title{
The Belfast Declaration: Promoting and Supporting Optimal Critical Care Nursing Practices Worldwide
}

\author{
European federation of Critical Care Nursing associations (EfCCNa) \\ European Society of Intensive Care Medicine (ESICM), Nursing and Allied Healthcare Professionals \\ (N\&AHP) \\ Society of Critical Care Medicine (SCCM), Nursing Section \\ World Federation of Critical Care Nurses (WFCCN)
}

Key words: critical care Declaration * international * nursing practice * standards *

www: http://www.efccna.org/ http://www.esicm.org/nursing http://www.sccm.org/Member-Center/Sections/Pages/Nursing.aspx http://wfccn.org/

\section{SUMMARY}

- Supporting and advancing critical care nursing is a priority and focus area for global critical care nursing organizations.

- Four major international critical care nursing organizations EfCCNa, ESICM-N\&AHP, SCCM, and WFCCN - are supporting, promoting, and elevating standards of practice for critical care nursing worldwide.

- The Belfast Declaration was established in recognition of the First Global Critical Care Nursing Organizations Joint Meeting, held in Belfast, UK in February 2017.

\section{PREAMBLE}

Supporting and advancing critical care nursing is a priority and focus area of the global critical care nursing organizations. At the European federation of Critical Care Nursing associations (EfCCNa) meeting in Belfast, Northern Ireland, held February 15-18, 2017, the inaugural Joint Session of the critical care nursing organizations - EfCCNa, the European Society of Intensive Care Medicine (ESICM), Nursing and Allied Healthcare (N\&AHP), the Society of Critical Care Medicine (SCCM) Nursing Section, and the World Federation of Critical Care Nurses (WFCCN) - was held. Collectively, these leading critical care nursing organizations represent over 600,000 critical care nurses worldwide.

The Joint Session highlighted the work of each individual international critical care nursing organization and it became evident that each organization, individually, as well as collectively, was advancing critical care nursing practice. Through educational initiatives including congress programming, web-based resources and other education-based projects; clinical support initiatives including clinical competency and skill building resources and tools; research projects targeting key critical care practices such as prevention of pressure injuries, fall reduction, promoting early mobility in the ICU, and patient and family centered care research among others; and through administrative support resources such as metrics for determining appropriate staffing in the ICU, supporting ongoing professional education, and promoting specialty certification in critical care, the international critical care nursing organizations - EfCCNa, ESICMN\&AHP, SCCM, and WFCCN - are supporting, promoting, and elevating standards of practice for critical care nursing worldwide.

\section{THE BELFAST DECLARATION}

The Belfast Declaration is hereby being established in recognition of the First Global Critical Care Nursing Organizations Joint Meeting.

The organizations pledge to the following:

- Identify opportunities to collaborate in further advancing critical care nursing education, practice, research, and policy.

- Advocate for the highest standards of critical care nursing practice worldwide.

- Advance the state of critical care nursing globally, including supporting further development of education and practice in resource limited countries.

- Advocate for multiprofessional team based practices where the contributions of all members of the team are acknowledged, supported, and promoted.

- Advance patient and family-centered care and engagement to support care and recovery of the critically ill both within and after ICU.

Contributors

- $\quad$ Eva Barkestad, Board Member, EfCCNa

- Bronagh Blackwood, President EfCCNa

- $\quad$ Stijn Blot, Past-Chair, ESICM N\&AHP

- Carole Boulanger, Chair, ESICM N\&AHP

- Paul Fulbrook, President, WFCCN

- Adriano Frignovic, Vice-President WFCCN

- $\quad$ Ruth Kleinpell, President, SCCM; Past-President WFCCN 